\title{
Emerging challenges of vector-borne diseases for Canadian cities
}

\author{
Luka $\mathrm{N}^{1 *}$
}

\author{
Affiliation \\ ${ }^{1}$ Schools of Architecture and Urban Planning, McGill University, Montréal, QC \\ *Correspondence: nik.luka@mcgill.ca
}

Suggested citation: Luka N. Emerging challenges of vector-borne diseases for Canadian cities. Can Comm Dis Rep 2016;42:217-8. https://doi.org/10.14745/ccdr.v42i10a12

\section{Background}

In Canada, questions of resilience, robustness and health have become prominent in debates about city-building in recent years. Climate change and increasing chronic disease are now central to debates on urban policy. Planners, architects and other specialists of the built environment are now engaging more fully with peers in other disciplines, but relatively little is known about what the emerging challenges associated with vector-borne diseases (VBDs) mean for urban design and planning in Canada.

\section{Objective}

Synthesis of key themes arising from a workshop on VBDs in Canadian cities held at McGill University in April 2016 in terms of urban design and planning.

\section{Narrative}

At the two-day workshop, expert participants from many backgrounds important to public health (notably psychiatry, epidemiology, zoonotics, parasitology, microbiology,

immunology, landscape ecology, geography, political philosophy, urban planning and civil engineering) shared thoughts on a wide range of issues that intersect in complex ways. What follows here is a brief description of the questions (and implications) regarding how metropolitan regions in Canada are planned, designed, built and maintained, and the potential impacts on VBD propagation. These are articulated in terms of five key points for future development.

There is an unambiguous need for increased interdisciplinary and intersectoral discussion of infectious VBDs and chronic conditions as they impact the Canadian population in cities, suburbs and periurban contexts, where the vast majority of Canada's 36 million inhabitants spend their daily lives (1). As all levels of government embark on ambitious projects of infrastructure renewal-especially in the ageing postwar landscapes that constitute the bulk of our metropolitan regions-there is a renewed need for policymakers, planners and elected officials (who control public budgets and priorities for implementation) to engage in detailed, action-oriented exchanges on what can be done. Emerging challenges of VBDs must be addressed as well as chronic conditions linked to sedentary lifestyles, which have attracted considerable attention in the last 20 years as we have become more aware of the 'upstream' contextual factors affecting public health-such as urban form that requires its users to be car-dependent for everyday activities.

Tradeoffs with other social, economic and cultural considerations must be identified and discussed. Contradictions arise among objectives, desirable outcomes and strategies that we can undertake in ways that are both timely and feasible (socially and politically). Certain tensions are apparent between what can readily be done to deal with chronic diseases-many of which are linked to the physical configuration of our metropolitan regions, e.g., urban form, density and 'walkability' $(2,3)$-and VBDs, which are often exacerbated by the various sorts of mediating measures taken to deal with chronic diseases. For instance, walkability is known to increase when people and activities are compressed in space (i.e., density), but this then calls for increased biomass (i.e., trees and other vegetation) to offset urban heat-island effects and the psychological discomfort many individuals have with crowded, densely-built neighbourhoods. Onsite storm water management (e.g., retention ponds) is now seen as desirable in urban and suburban contexts to prevent unnecessary stress on ecosystems and sewerage systems, but ticks and mosquitoes (notorious vectors for Lyme disease and the West Nile virus, respectively) may thereby have ample opportunities to proliferate. These are core questions of resilience and adaptive design as taken up in other areas of planning (4-6).

Issues of scale (scalability) and the resolution of information available to key individuals at different points on the evidence-to-policy-to-practice 'pipeline' are important. How should we identify, analyse and understand issues? How can effective responses then be developed and implemented given existing constraints? How should we monitor and adjust various intervention strategies? Specific concerns include 'who does what' (different levels of government), data quality and continuity and knowability (i.e., the robustness of the models used to predict outcomes under different conditions).

How can we face the real (practical) limits of planning and policy, especially in liberal democracies? Dealing with VBDs and chronic conditions in metropolitan regions is what political scientists call a 'wicked problem'. Specific themes that were invoked at the workshop include public trust, the nature of authority and control, and the quality, efficacy, and timeliness of decision-making in deliberative democracies. 
Finally, a question: What sorts of mechanisms can we develop to ensure continuity and efficacy in terms of strategies appropriate to issues as they become more or less important over time? Three points bear noting. First, knowledge production and dissemination/translation, i.e., how to increase awareness among non-specialists and (especially) among different groups of specialists in various sectors relating to public health, policy and urban affairs. Second, how to overcome the silos that tend to develop within and across sectors of policy and practice. Third, revising the distribution of responsibilities among levels of governance in Canada, since municipalities are forced to balance competing objectives through planning (notably including land development to maintain their tax base, which finances a wide array of services and infrastructure), and yet remain weak in terms of exerting real control over land development and securing adequate operating budgets though taxation. The topic of vector-borne diseases highlights the unmet challenge of balancing subsidiarity and paramountcy (in legal terms) or centralisation (in institutional terms).

\section{Conclusion}

The tensions and challenges revealed among different policy goals and objectives are not new in broad terms-similar issues have been discussed by Agyeman (7), Fainstein (8) and in two new collections edited by Dale et al. (9) and Reed \& Lister (10). The interaction among the workshop participants suggested various paths to follow and important gaps that demand to be addressed. In particular, a structured symposium could be organized, one for which invitees would prepare detailed position papers and through which an agenda for in-depth research could be articulated, possibly leading to focused applications for collaborative interdisciplinary research.

\section{Conflict of interest}

None.

\section{References}

1. Gordon DLA, Janzen M. Suburban nation? Estimating the size of Canada's suburban population. J Archit Plann Res 2013;30(3):197-220.

2. Ewing R, Handy S. Measuring the unmeasurable: urban design qualities related to walkability. J of Urban Des 2009;14(1):65-84.

3. Manaugh K, El-Geneidy AM. Validating walkability indices: how do different households respond to the walkability of their neighborhood? Transp Res D Transp Environ 2011:16(4):309-15.

4. Burton P, Mustelin J. Planning for climate change: is greater public participation the key to success? Urban Policy Res 2013;31(4):399-415.

5. Lister N-M. Resilience: designing the new sustainability. Topos, 90 (Special issue: Resilient Cities and Landscapes) 2015a:14-21.

6. Lister N-M, Brocki M, Ament R. Integrated adaptive design for wildlife movement under climate change. Front Ecol Environ 13(9) 2015b:493-502. doi:10.1890/150080

7. Agyeman J. Introducing just sustainabilities: policy, planning and practice. London: Zed Books / Palgrave Macmillan; 2013.

8. Fainstein SS. Can we make the cities we want? In Beauregard RA, Body-Gendrot S, editors. The urban moment. Thousand Oaks CA: Sage; 1999. p. 249-272.

9. Dale A, Dushenko WT, Robinson P, editors. Urban sustainability: reconnecting space and place. Toronto: University of Toronto Press; 2014.

10. Reed C, Lister N-M, editors. Projective ecologies. New York: ACTAR; 2014. 